\title{
Street Children: Circumstances and Problems of Street Children in North Western Ethiopia Amhara Regional State, Central Gondar Zone
}

\author{
Biset Yalew \\ Department Of Sociology College of Social Science and the Humanities, University of Gondar, Ethiopia
}

\begin{abstract}
The purpose of this study was to show the general circumstance that is accounted for the phenomenon of street children, and problems in the study area. Thus, it examines the contributing factors that push children to be on the streets, encounters, and their experiences in their endeavour with street life. The study employed a qualitative method to get rich information about the actual life of participants. The study employed a Phenomenological design to investigate the daily life experience of street children. Purposive and snowballing sampling techniques in this study were employed to get participants. The sample size for this study was 23 participants in which 12 of them participated in an interview and 8 participated in focus group discussion and 3 key informants' interview. The collected data were analyzed thematically. The findings of the study showed that children joined the street due to lack of family planning, divorce, parental detachment, poverty, attending religious education, abuse and neglect, peer pressure. The result also showed that children on street encountered rape, taking away their properties, chased away by Militia patrol and police; they are facing social exclusion, and health problems due to their dwelling conditions and inaccessibility health services. Thus, street children additionally face more troubles once they are on the street that is surely going to have an effect on their development.
\end{abstract}

Keywords: street children, circumstances, problems

DOI: $10.7176 /$ RHSS/10-23-01

Publication date: December $31^{\text {st }} 2020$

\section{Introduction}

1.1 Background of the Study

The issue of street children is a serious and worldwide problem. It is alarmingly increasing occurrences that have been extended in many countries due to the rapid growth of urbanizations and the development of industrializations (Waghid, 2014). There are various reasons why children living on the street. The circumstances of street children are varying from country to country, since; it depends on the level of economic development, cultural, traditional setting, institutional intervention, level of social coordination and peace (Kibrom, 2008). Street children constitute a multifaceted phenomenon that can be divided into at three categories: children on the street, children at risk, and children of the street (UNICEF, 2012). Children on the streets are children who are working on the streets in order to survive (Lalor, 1999). Children at risk include the urban poor who form a reservoir of street children. Children of the streets are living and work on streets (Densely and Joss, 2000).

Thus, Street children are emerging due to war, poverty, loss of traditional values, domestic violence, physical and mental abuse and constitute a marginalized group in most societies. The permanent experience of unforgiving environments and the nature of their lifestyle make them vulnerable to and it may lead to mental, physical, social, health problems, abuse and neglected (Hecht, 2003).Hence, street children face many difficulties, living in their living conditions, suffering from hunger, harassment, physical abuse, and deprived of basic services such as education and health care (Vanessa, 2007).

\subsection{Problem Statement}

Street children as a social problem are common in the world and more prevalent in developing countries (Deriba, 2012). To make a street child, there might be several covert and overt reasons (Bodo, 2014). Cities are increasing due to multifaceted socio-economic, political, and natural situations in Ethiopia (Kebede, 2015). The reasons which lead children to the street and childhood marginalization in Ethiopia came from complex socio-economic, political, and cultural situations (Tatek, 2009). Due to various correlated circumstances and composite socioeconomic problems, there is a large portion of children living in extreme poverty (Boafo, 2015). The proportional number of street children in Ethiopia is, Addis Ababa, Adama, Gondar and, Hawassa (FSC, 2003, cited Birhanu, 2019). Due to this proportional order, number of street children in Gondar city is high. Thus, this, research was investigated the major circumstances and to show the foremost problems facing on street children in Gondar city, Ethiopia.

\subsection{Objectives of the Study}

The aim of this research study was conducted with the purpose of investigating, circumstances and to show the 
foremost problems facing on street children in Gondar city Amhara region, Ethiopia.

\section{Methodology}

\subsection{Research Approach}

For the purpose of achieving the objective of the research, this research used qualitative research approach. This approach is helps to provide the rich data about the real life of children situations. It is a form of social inquiry that focuses on the way children interpret and make sense of their experiences in which they live. It seeks to answer questions framed with what and how often a given phenomenon occurs (Creswell, 2009). Qualitative researchers are more likely to deal with constraints of the everyday social world (Denzin \&Lincoln 2000; Seidman 1991). Therefore, qualitative method was proved to be appropriate in trying to answer the specific research tasks of studying children experience. Owing to this, qualitative research in this study due to the nature of children's daily lived experience. Thus; the data was usually seen as rich, vital, of greater depth and as more likely to present a true picture of reality regarding objective of the study.

\subsection{Research Design}

In this study phenomenological design particularly bracketing of a qualitative research method was applied to investigate the everyday life experience of street children. This research design is a way of describing phenomena that exists as an integral part of the world in which we are living (Astalin, 2013). This research design was attempted to understand how participants made sense of their experiences before and after coming street, faced problems. The researcher sets aside his or her own experiences in order to understand those of the participants in the study (Nieswiadomy, 1993). To make the research feasible with the available time, and resources, the researcher employed a phenomenological design with a cross sectional study design. This design is a critical reflection of conscious and lived experience in terms of the individuals' relationship with time, space, and personal history in order to understand social reality (Grounding, 2002).

\subsection{Sampling Technique and Sample Size}

The choice of the sampling scheme is an important consideration that all researchers should make and it helps to inform the quality of inferences made by the researcher that stem from the findings (Anthony and Nancy, 2007). To collect relevant data from the primary sources, the respondents have selected through none probability purposive and snowball sampling. When developing a purposive sample, researchers use their knowledge or expertise about some groups to select subjects who represent this population (Berg, 2001). The purposive sampling technique is the deliberate choice of a participant due to the character of the participant and simply the researcher decides what needs to be known and sets out to find people who can and are willing to provide the information by virtue of knowledge or experience (Bernard, 2002).

As well, Snowball sampling is a method where the researcher identifies one or more individuals from the population or group of interests. There are a lot of children on the street which made it difficult to get easily on my initial visited in the settings. The researcher often went to the settings and spent a lot of time in the settings in order to establish some relationship with street children. Until a street child was agreed to be interviewed, and the interview was actually carried out, the researcher contacted with some streets and then they were brought their friends. Therefore, sample size of the study; the researcher obtained the appropriate data from the respondents, until the data reached the point of saturation while qualitative data is determined by a point of data saturation. In order to saturate the data on the subject relevant to the objectives of the study, the researcher conducted in-depth interview with 12 participants, 8 focus group discussion and 3 key informants. During sampling process, there are some factors and situations which dictated either inclusion or exclusion in the study based on their degree of relevance, and insights with the objectives of the study. Therefore, this researcher set the inclusion and exclusion criteria to identify the participants of the study. The inclusion criteria include; street children, whose age is from 12-17 years old and living on street 1 and above due to their ability to describe the circumstances, and faced problems in the study area. Since, it helps to obtained reach data from those street children owing to the experiences of street life. Consequently, both boys and girls are being on the street between 12-17 ages that are living on the street in Gondar city, were included. While, the study also excludes street children below 12 years old, and their duration of time to stay in the street is less than 1 years due to lack of ability to describe the reasons, and problems in the study area, since, they might not be able to experience the issue under study very well.

\subsection{Data Collection Techniques}

To collect the data, the researcher considered scientific rules of qualitative data collection method. This study has triangulated different methods, sources and data in order to do away out of the major dilemma of research, absence of a single satisfactory method of empirical investigation (Yogesh, 2006). Thus, the researcher used and employed different data collection instruments in order to get relevant and sufficient data that were needed in the study. After that the researcher met street children in their living place to take them in the field with me. The researcher prepared 
a convenient time and place to conduct in-depth interviews and FGD, because it was helped to avoid fears and suspects. And to increase the cooperation for the study from key informants; the researcher made prior contact with the directive administrator of women and children affairs, hope for tomorrow NGO coordinators and a police directive heads as well. Subsequently, the researcher explained the purpose of the study to get their approval easily.

\subsection{Data Analysis Procedure}

The procedure of data analysis is a process of reducing a large amount of collected data to give meaning in accordance with the purpose of the study (Erlbaum, Taylor, 2009, and Girmachew, 2006). The data was analyzed and interpreted thematically following different procedures. Thematic data analysis intended to provide a framework for the analysis of qualitative data and by providing ways to manage themes and data, (Bray man, 2008). The circumstances of children living on street problems which are faced on might have various themes. Thus, the data which were collected via in-depth interview, key informant interview and FGD were analyzed thematically. The procedure of thematic analysis follows several steps: those are familiarization, transcription, organizing, coding, and themes (Lacey, 2007). Before data analysis, the researcher became familiar with the collected data from the in-depth interview, FGD, and KII. Afterward, the data were transcribed and translated to the study language. Then, the data were coded in order to classify similar themes. The qualitative data were analyzed by constructing a general response category of each individual respondent. Finally, the general ideas of the information from the respondents were presented through words and accesses of the opinion of the respondent.

\section{6; Data Quality Assurance}

Reliability is the degree to which the finding is independent of circumstances of the research and validity is the degree to which the finding is interpreted in a correct way (Lucchini, 1996 and Grimachew, 2006). The informants understanding of the relevance of the study and their willingness to participate affect the validity of the data. The researcher gave them a comprehensive introduction about the nature and importance of research to enable them to respond freely. Along with the researcher set a very clear objective and attempt to familiarize me with respondents before the researcher started any kind of data collection. The purpose of data quality assurances is to guarantee the trustworthiness and honesty of the data by reviewing relevant secondary sources which back and by cross-check, the reliability of the data collected. Specifically, the researcher applied the entire interview guides were checked before field reach, the data thoroughly related, recorded data was cleared, and data analyzed systematically.

\section{Findings of the Research}

\subsection{The Major Reasons that Stirred Children to Join Street Life}

3.1.1. Family related issues

The finding mainly indicated that family-related issues, poverty/ economic scarcity, cultural issues, abuse, and neglect are the reasons for children living on the street in the study area. In this regard, a 13 years old street child reveal show he tempted/ encouraged and made his decision living on the street as follows:

I came from Keble 3, in Gondar city 6 years ago. My father was working in a picket at the Gondar factory. And my mother also hired to bake Injera and Abishilo for different persons. However, my father was always drinking alcohol during his rest time, and he has beaten my mom in the evening because he was overtaken alcohol. And that disturbed us too much. After that our parents were divorced, and that we lived with our mother but she couldn't afford to help us because her income was too small. Then I joined street life which is a miserable life.

Therefore, from the above descriptions, it is understandable despite the likelihood of children making a choice and to extend the demand of children living on the street. The overtaking alcohol is provided by divorced parents. When divorce occurs, it is accustomed that the mother or the father of the child obligated to fulfil the basic needs of the child such as food supply, cloth, school expenditures. However, usually, the provider is reluctant to fulfil these needs which lead to a high quarrel and conflict between the parents of the child. A single parent is very vulnerable to the stresses which will result in force children out of the home. The collective efforts in caring and protecting children are not found in such families. Due to the lack of care, protection, and unfitness of coping for their children, many children leave with no alternative home. Another 14 years old street children articulated as follows:

I came from Dabate 3 years ago. 5 years ago my parents were divorced. Currently, they are living together at Dabate, but they always quarrel. The reason for their disagreement was envy while my father is blind and he always asked for the mother who was with you? This creates abhorrence on me and I distanced myself from my parents. After that, I was forced to live such a miserable life. Since I left my parents, I spend gruesome life on the street.

Accordingly, the above quotes showed that children were forced to depart home and be inherent on the street are influenced by the family's relationship in the house. The jealousy between parents makes it more difficult for family to sustain the cohesiveness at home. The children were forced to depart homes and reside on the streets due 
to parents' relationship. There are families where children must go out to find food and some end up in the streets. As a result, family relations at home were contributed to children's living on the street under very harsh conditions. FGD descants 'discuss as follow:

Most of the time the people thought our first arrival on the street issues to economic problems; however, a number of the children left from home due to parental disagreement within the house. Because of disagreement at home, we couldn't get affection, care, and protection. It is because the dad disagreed with mom, then children autonomously decided to depart home and we started on the street. Then we spent a miserable life. Thus, this quote showed that most children take to the streets because of lack of parental affection to children at home. Due to the poor relationship of parents within the house and the lack of affection for children, they decided to leave home. Their parent's disagreement at home is preferred to the street. Thus, owing to the children do not get parents affection, care, and protection, they involved insecurities experience on the streets. Children experience a lack of affection, care, and maltreatment at home due to parents' relation, which is neglected from education and in the broad social interaction of the community.

Furthermore, an Interview with key informants of police directive in central Gondar zone who is serving as a vice commander described as follow:

In fact, there are different reasons that have encouraged children living on the street in Gondar city. From those factors, lack of birth control is provided in wagera, west Blessa, East Belssa, and KinfazeBegela because Safety net program has existed to assist for fewer income individuals depending on the number of families so that they increase their child to urge assistance from this program. Then, in one home lots of children are there and that they couldn't get basic needs as the lands are not fertile. Thus, they decided to depart home and began living on the street.

As a result, the above excerpt showed that around Gondar, the fertility of the land is low, and so the government established a safety net program to monitor their poverty, however, the societies give lots of birth to children and parents migrate with the number of children from rural to urban. Safety net program in low-income families have led to significant levels of migration of children with children. As a result, the family circumstances perhaps contributed to children living on the street. Which means that due to low fertility rates of the land in several districts, around Gondar the government provided Safety net programs to assisted low-income societies, thus to get the help they need not use birth control. Parents place greater value to give birth children to get assistance than use family planning. Because of having a need for assistance from the safety net, it is a habit for children to increase in one family.

3.1.2. Economic Scarcities / poverty

The finding of the study showed that the majority of the children left home due to economic problems. Economic problem plays a primary role in pushing children to streets, in order to take care of their live. In this regard, a 13 years old child reveals how she left home and living on the street as follows:

I came from Keble 18, 3 years ago. My parents are working on cereal masher to obtain a powder. This powder wasn't enough for all family members. We live in a rented house and we pay 450 birr's; however, we couldn't pay for the rent on time. During that time, I was 10 years old and grade three students yet, I couldn't continue my education, because my parents forced me to start begging. Then, I dropped out of education. And, I started begging around the mosque in Keble 18. However, 1 year ago I've been living Arada and piazza.

It is understandable how children live on the street and maintain their life on the street. The vulnerable children living on the street got from their family's economic background. Most families live on overcrowded slum areas of the urban centres and their income is incredibly low. Then children take and opted to live on the streets to get better opportunities because there's no money for education. Within the same case, they are influenced by parents to travel to the streets, in order to seek help. Furthermore, street children in the study area work in family-based activities as part of the informal economy. Hence, children come from a very poor family and stopped going to school so as to support their families economically. It indicated that Parents place greater value on children being employed in economic activities than going to school. It means that poverty is forcing more children to the streets. Another 14 years old street child said on his part as follow:

I came from Belesa 4 years ago. My parent's livelihood is agriculture yet we couldn't provide our basic needs. Obviously, the fertility of our land is uncomfortable for agricultural production. Thus, we haven't enough land and might not produce and feed the family as should be. Then my father hired other farmers in summer, however, the hired person couldn't provide our basic needs. Moreover, we sold our lands for two or three years in cash. When I was 10 years old my parents decided to rent to our uncle and that I was hired to keep cows for one year. I heard information about the urban areas; there are better working opportunities to get accessible resources relatively to rural areas. Later I decided to left home and living on the street to get better opportunities in the urban areas.

Thus, the children looked as if it would have an association with the onset of family poverty and complicated life on the street. Because of poverty at home, the children assumed that there will be an opportunity in urban areas. Additionally, there are circumstances that children are obligated to do what the parents want to do. Children are 
forced to hire without their permission, in the return of little amount for their parents. Children living in families with these factors there is inadequate education and the family is not part of a strong economy. Thus, to get better opportunities in urban areas, it makes children of poor families end up in towns in search of a more satisfying lifestyle.

Likewise, Interview with the key informant in central Gondar women and children affairs directive who is serving as a professional of children right and security illustrates as follow:

Our institutions always attended street children and as we identify most of the street children were coming from lower-income parents. As the professional, we contact them, since, their parents couldn't cope, therefore the children reside on the street are mainly influenced by the economic problem. Thus, most street children came from the agricultural area because of a lack of basic needs, since their parents couldn't afford their children. Then they migrate from rural to urban areas to full fill their basic needs.

Thus, the problems of poverty in some of the street children's families decided the child living on the streets as a substitute for their homes. Most rural family poverty, are unable to provide economic support to the children then they decided to move out of the home. It means that a number of economic hardships children at home made them come and stay on the streets. Poverty has been cited most often because of the reason for the bulk of children to interact in street life. As a result, children migrated from rural to urban and that they started living on the street. Since children agree with the complexity of urban streets are the art of survival.

Additionally, Interview with the key informant in central Gondar police directive, a vice commander revealed that children could find out deacons or spiritual education.

Through our visiting as the concerned bodies, a number of the male street children become deacon. Due to a lack of a bit of help; they have to figure out what to buy cloth, soap, and other desired amenities. Then, they deceive the firm from time to time and they later decided to live on a street where they forgot their former objective. Thus, they move to the bus station to get a knot.

Therefore, some street children are available in town to attend spiritual education at the Orthodox Tewohido Church. Although they obtained shelter and food from societies, it's clear that they have no income sources than looking for workaround mill house and taxi station because they are going to get what they need. Due to this, the learning process is missing because they are attracted by money to survive. It showed that spiritual education has its own role to increase street children in the study area.

3.1.3. Socio -Cultural Issues

Another and quite a significant reason for children living on the street may be a cultural factor. In this regards a 16 years old child articulated as follows:

I came from Belesa 2 years. When I was 15 years old, I was taking some money from home to gambling. And that I return home late, however, except mother the father failed to know what I was doing. Then I did repeatedly and in an unspecified time, our oxen were vandalized when did gamble. Then mother told to father, about my gambling, and the he beat me with a stick. However, I couldn't leave gambling. Subsequently, all neighbours labelled me as a bad character and deteriorated their children through gambling. Then my parents punish me in the evening. As a result, I had gotten free space on the street and now my life is miserable.

Thus, the above narration tells us how the rural community residents forcing the child to leave home. It will be understood cultural problems forced them to depart home. Due to the assumption of the children created a polluted image towards themselves and societies then their completion to leave home. The family is against their children both physical and social violence due to the culture of society. These situations create a fertile ground to give a number of street children. So, due to unwanted activities done by children in the given communities, the families against their child and they left home to live on the street

Additionally, key informants described as follow: Our institution is working with street children. Varieties of street children are forced to the early mirage. This early marriage has been habited within the rural family and it had been given still without the permission of children for unknown persons and in a hidden manner of government officials. The parents are also marrying a female so as to escape from poverty. As well, the parents assume that the daughters will sexually expose the essay and bring unwanted pregnancy. The daughters drop out of education and marrying with an unknown individual. Then, these kids disappear from their husbands. Subsequently, if they're going to choose their parents, their parents don't volunteer to accept them. Thus, they opted to travel to towns but unable to get according to their expectation. Then they're going to be beginning living on the street and that they are easily exposed to sexually transmitted diseases like AIDS and unwanted pregnancy. Due to economic hardship on street, they involving commercial sex worker. Thus, the early marriage for females helps to expand several social and economic benefits to parents and relatives. To escape from poverty, families used their children as traditional functions of fading/ income. It indicated that due to economic pressures on the family, many of their primary functions have come to an end. In the culture of the society at large, parents arrange an early marriage for their children, mainly for daughters, in a hidden manner without the knowledge of government officials. This reinforces the withdrawal of children from education. The cultural systems are providing the failure of function properly with respect to protecting their children impacted negatively. Many parents believe that daughters never 
continue their education because of the assumption that being exposed to premarital sex and unnecessary pregnancy, which underpin the drop-out of many girls from school to get married. As well, girls providing commercial sex to full fill their basic needs.

3.1.4 Abuse and Abandonment

The finding of this study showed that some participants living on the street do not seem to due to their stepfather or stepmother but instead they are exposed to vandalism of property and ethnic conflict. In this regards a 12 years old street child revealed that, why he choices street home.

I come from Ambagiergis 2 years. My parent's livelihood is cereal trade. When I was a grade 6, in 2018, I have gone to a school infrequently because my father not permitted to attend daily. This year we changed our rent house and that I have carried TV but it had been broken and my dad is very sad and beaten me by a stick. Consequently, I was to interrupt and came to Gondar in piazza. Then I was begun to living on the street with no compassion.

As a result, street children are forced by parents who wanted to streets; hence, many parents did not consider the future of the child. They might not realize that whether a person is most persuaded by the one or the opposite what he /she must rely on and desire is knowledge of the future. Moreover; parents close doors to opportunities like education and exposure to the street. Children are physically thumped by parents or caregivers because of the response that the child was in a certain mistake. Thus, due to abusive families, the children cannot find love and care at home, as a result, they left home and living on the street. Additionally, a key informant of central Gondar zone police directive who is serving as a vice commander described as follow:

While there are factors that are leading children living on the street, a number of street children are forced by

political disagreement. It's because they are very exposed easily to street lives than search for other

alternatives. We have a task to assist street home children, so multiple street home children are caused by ethnic conflict especially, Tikildingay; Chillga/ayikel and Ambagiorgis infrequently.

As a result, the cause of the street child in the study area is ethnic conflict. The innocent children are stricken by the ethnic conflict that had been taken place by individuals serving political profit forcing blameless children to the street. Children have often not been considered as subjects having the ability to create their own autonomous decisions rather a particular extent determined by issues they are facing.

3.1.5. Peer Pressures

This study findings from in-depth interviews with street children, FGD and, key informant interviews result illustrate that street children are attracted by their friends especially returnee since the returned individuals were wearing new clothes and that the returnees are preached in order that they deceit by attractive materials. In this regard, a 13 years old street child explained how he left home as follow:

I come from Gondar Keble 3, 3 years ago. When I was 8 years old my friend was living on the street and he returned to his mother's home in the evening. We are neighbours and that we met in the evening. After I meet with him, he told me that there are plenty of chances, in piazza around telecommunication building. He told me that if I serve cafe users, they will provide me with money. Additionally, if I stay on-street, NGOs will assist me in new clothes, food; and infrequently I may obtain 300 birr's per month. Then I left home and living on the street by his misinformation. After I have come to this life, there are a lot of challenges facing me. Although I need to return home, I felt shame and confused.

Consequently, the above quote showed that peer pressure has an important source of information about street life. Before a child leaving home, the experienced peer preached to new arrival street child and new demands will accept. The new arrival street children are deceived by the clothes and assistance of NGOs. Thus, peer's misinformation about street life, the new arrival children facing challenges due to inexperience. They are confirmed all information from experienced street children without hesitant life of the street. Then such things get the children more and more confused where they belong

FGD participants revealed that;

Because of misinformation about the cities, we are in this life. There are pulling factors that drew us within the cities by older and experienced streets child. Before we came here, there are opportunities that are better than our current life. This discussion revealed that in the street, especially at first arrival, they expected a better job in cities. This is sometimes also used by older children as a process of socializing newcomers into the street. Although, the condition of better resources that originate from the new pulling factors in the cities informed by peers, the children are misleading to live on the street.

\subsection{The Problems Faced With Street Children.}

In this study variety of problems face street children within the study area. The finding mainly indicated that, health problems, insufficient basic needs, abused and negligent are the problem facing on children living on street in the study area.

3.2.1 Health problems

The health condition of street children in Gondar is very problematic. Many streets children suffer from malaria; diarrhea, TB, and HIVAIDS since they reside in unclean surroundings, dirty, and a number of other environmental 
hazards in the city. In this regards a 14 years old street child stated as follow:

After I started living on the street, yes, the health problems encounter me. Those health problems are coming from multiple directions. Among those, lacks food, poor sanitation of the sleeping area, and also the lack of clinical treatments. Once I fall and slashed my leg however, I couldn't get clinical treatment on time. At that moment, I hoped to get clinical healing; but it took a long time to travel hospital. Also, the bureaucracy is simply too boring beyond health problems; health service was easily accessed.

Thus, the children who are living on the street have lack basic needs and access to health institutions within the study area. It showed that due to lack of health service, safe sleeping areas, and food, they are in danger of health trouble easily. As well, they do not have easy access to health services and they go a long process to get documents/kupens to go to the clinical institutions. Moreover, beyond health problems, the bureaucracy is boring them. As a result, the lack of access to health services and its bureaucracy caused street children's health problems beyond their lack of basic needs. Consequently, children face health difficulties and lack of health service access to lead harmful to them. Another 12 years old street child articulated as follow:

After I started living on the street, I become hungry. Subsequently, I went to hotels to find leftover foods. Occasionally the workers chase me away because they saw me as a thief. Due to improper feeding systems and eating leftover foods, I exposed by disease, diarrhea and I was not getting any medical treatment.

Therefore, it showed that children living in the streets in the study area face various health problems as of their lack of access to nutritious food, and medical care. Eating patterns of street children, there were different diseases facing them because as the data shown in this study, street children dependent on leftovers from hotels, garbage bin. Although the children have been disadvantaged and harsh heaths on street life, they could not get medical treatment accordingly. As well, they chase by workers of the hotel during the search of leftover foods owing to the labelling of street children are thieves. Along with they could not get leftovers, during starving then they were exposed by disease easily.

FGD discussant discussed as follow:

After we live on the street, there are problems that we faced. It's because we have not given credit for our hygiene while we've not taken a bath and drink dirty water that is contributed to our health difficulty. And also, we've no placed to sleep; therefore, we are sleeping on the outdoor. Consequently, the foremost serious unhealthiest is that we have got no income. Thus, the data showed that street children could bar in any health problem due to lack keep their basic hygiene. So owing to a lack of personal hygiene, they bared health problems. It indicated that a lack of sanitation and drinking dirty water contribute to poor health because they give priority food. Moreover, they are sleeping at night in the veranda. Due to sleeping at the corners/ veranda, they are constantly exposed to harsh climates like intense sun, rain, and cold. Therefore, they are the neglect group of societies and do not have the capacity to requisite function. The failure to make an appropriate source of income and the helpful environment has an undesirable effect on health. It showed that they have already experienced the difficult circumstances of lives. Additionally, Key informant of women and child affairs central Gondar zone directive who is serving as child right security reported as follows

As is known, our institution appraises the institutional plan. Because of their problem, we contact them in the day time and sometimes in the evening with the police. A serious risk for Street Children is they are exposed to disease easily because they are raped at the times of darkness in their sleeping area. Street girls are exposure to sex-related vulnerability and transmitting diseases, like HIV AIDS and, unwanted pregnancy. When they exposed to sex related vulnerability, there are a lot of challenges faced like unsafe abortions and sicknesses associated with pregnancy. After birth, nobody is following up on a child and mothers; infrequently our institution helps them by giving the children to adoption but the child will be exploited due to working over ability like a shopkeeper, and as a waiter.

Therefore, this study showed that their lives, sleeping, and working conditions are reasons for street children uncovered by health difficulties. Owing to sleeping sleep at the roadside, they raped at night. It showed that as exposure to sex-related vulnerability, they suffered from STD like HIV AIDS in the cities, because they sleep together and that they contacted one another. This disease follows from inadequately targeted health service provision for the vulnerable group of individuals within the study area. Furthermore, due to the rape of street girls, they provide giving birth and unwanted pregnancy. It means that street girls endure the most gruesome sexual attack.

3.2.2. Inadequate Basic Needs

This study showed that children living on the streets carry a huge burden on their shoulders. Every aspect of their living is affected. Therefore, their basic needs aren't met including; shelter, food and water, medical attention, clothing, schooling, and sanitation. In this regard, a 15 years old child articulated about the shortage of basic needs illustrated as follows. :

I came from Gondar 8 years ago. After starting to live on the street many problems encountered me. Among these problems insufficient, food, shelter, and garments are the most acute my life, particularly finding food and shelter are the foremost traumatic for me. This made it hard to get food easily through begging because 
my age was the most determining factor to induce what I like. The beggars who are female and baby get something more pity than them is emotional. As well, I sleep on the veranda because I have no shelter. However, they chase me due to the societies assume street children are the trouble maker and threats of the city.

As a result, the data showed that although many encounters are facing in their everyday lives, inadequate basic needs are the most challenge them. Because of insufficient basic needs, most of the street children have developed means of finding food in different hotels. However, not all street children obtained leftovers from hotels. The beggars who are baby and female get something more of emotion and pity of them have sympathized. They perceived beggars who are female and baby on the street which give priority them. It indicated that there are gender differences and ages that determine the streets who beg on the street. The opportunities made available to those who make it more appealing to others. This also rejects the older street children have been confirmed by people. It means that although children are a pillar of the country and the backbone of society, their livings are insecure. More importantly, society perceived them as a threat to the city. As a result, this makes children psychologically damaged and feels humiliated.

Likewise, FGD discussants discuses as follow:

While we faced a variety of problems yet insufficient basic needs were significant issues for our life. Due to social exclusions, we couldn't get even leftovers and sleep outdoors/corners. Also, we were labelled us thief, picking a pocket, and telephone, so it's difficult to get any things. Having this mind, the study showed that due to isolation, feeling alone, and unable to help, they could not get their basic needs. It indicated that public perception of them is negative due to the hasting of street children is impolite and thief. From this study, it clearly understands street children's exclusion persists with the wide social and cultural problems due to impolite activities and labelling of a thief. It showed that street children further exposed to carry a social stigma. As a result, it separates them not to get assistance from society to survive. Additionally, key informants illustrated as follow:

As concerned bodies, we assess them infrequently based on the institutional plan. From our visits, we could identify their problem in street life. Thus, without any hesitation, they actually exposed to inadequate basic needs particularly foods and shelters and exposed to communicable diseases. And, due to inadequate basic needs, they involve in unwanted activities like picking pocket, burglary. As well, due to inadequate shelter, they sleep with dogs. This is because a negative perception of societies to them. And they are open to sexually relate bared by unknown individuals and by the older street.

Consequently, the above excerpt indicated that insufficient basic needs are common problems. The street child suffers from an absence of drinkable water, food, and shelter. Children who are constantly living on the street don't obtain basic needs. Thus, due to the dearth of basic needs forcing those unwanted activities. It means that because of unable to get basic needs they involving in criminal activities, like picking a pocket to survive their life. This is because the experiences of street children in relation to basic needs can be forcing into unwanted activities. Moreover, the negative perception of societies toward street children is the fundamental cause for most of the sophisticated nature of inadequate basic needs even leftover. As well, due to the barring of society's to street children, they sleeping with dogs at corners/veranda. This is because sleeping on corners/veranda; they are vulnerable to sexual attacks as well.

\subsubsection{Abused and Neglected}

The study found that street children are chase by militia patrol irregular time at midnight. The finding of the study showed that street children could not be supervised by both governmental and nongovernmental organizations in detail. It indicates how street children are overwhelmed by shocks and inhuman activities in their life. Of course, at the start, children come on the street already vulnerable, and gradually they experience a new set of life. In this regard, a 14 years old street child articulated as follow:

I'm starting living on the street for two years. I came from lay Armachiho particularly Sonja. When I came to Gondar for the first time, the police endeavoured to take me back to my parents when I was come to here. They harassed me through insult and that they wanted to return to my parents by force. However, I am not interested to return back in my parents because before I came to Gondar I always have gone to town without parents' permission. Thus, their attempt did not add up because I came due to my parents' abuse.

The failure of parents' affection and the beating of their children live on the street. Due to dysfunctional parent-child relation, the street children are badly treated by securities men in the city. However, the involvement of the police for the street children consistent with their duration of time, since they stayed focused on new arrival children in the city. Since streets children particularly boys encountered threats or were harassed by the police. Another 14 years old street child described as follow:

When am living on the street, various problems were faced with me. From those, social exclusion is taking the biggest share. The reason I was excluded from societies is that I've not given a cure for my personal hygiene. As well, society could not understand why I live on the street. Obviously, I couldn't care about my personal life due to lack of access and that I only give priority to food.

Thus, it makes them feel isolated, poor, and unable to help. The majority of the people are misinterpreting the happening of street children and they end up in exclusion. Moreover, street children lose the value of their 
existence because they could not take their personal hygiene therefore, due to this, society excluded them. Lack of affection makes their life full of challenge. As a result, they could not get help from society to survive. The data indicated that there are different contributing factors for the incidence of abuse and neglect to street children. Moreover, key informant of hope for tomorrow coordinator illustrated as follow:

In fact, most street children don't have a shelter, and that they sleep at the corners. Due to lack of shelter, they sleep together both males and females so they rape girls of midnight by unknown individuals. To your surprise, not only females but also males are raped, as a result, children particularly males are shocked and excluded by their members. Yet females also are affected by STD and fistula beyond psychological problems.

Thus, the above excerpt showed that street children are raped when they sleeping on the corners by unknown individuals. It showed that the street children particularly girl streets encountered by rape infrequently males are also affected. From the beginning street children are vulnerable; the raped street girls are barred by STD and fistula. Moreover, the raped street male child is a means for developing principally a deviant for societal norm and value. It showed that the raped street males are going to be gay and that they also expanded this unnecessary action. As a result, raped boys are affected by psychosocial problems and excluded from street children. There is also detection of the problem of homo sexual violence which is boy's rape perpetrated by adult man. Some adult men commit homosexual violence against boys particularly at night. Experiencing rape as a young child also increases the risk of further victimization and accumulation of violent experiences for the other street children.

\section{Discussion}

The data are discussed here thematically with information offered by the participants ordered logically in-line with interview questions and the theme it tries to cover. This was done in accordance with objectives of the study outlined. According to the results of the study, the circumstances leading children living on the street are family related issues, socio -cultural problems, poverty, peer pressure, abuse, and neglect. Thus, these findings were both consistent and inconsistence. A study finding of a family-related issues investigated by Njeru (1989) absolutely found that single parents have irregular incomes. Thus, due to the lack of standard income, many street children leave home to address basic demands. Because the family has failed, it's crucial that children providing basic needs, for them. These findings are consistent with this study, which identified family problems as a major reason for children living on the street. Thus, it articulated that almost all of the children weren't given sufficient food and that they decided to go away. However, this study also found that lack of birth control/ family planning and establishments of safety net programs forced children to leave home. Thus, with this study finding the establishments of Safety net programs and the assistance of a low-income group of societies from the safety net program in lower-income families weren't using birth control. Thus, this study finding has revealed that its own role a child leaving home four or five years of birth. And this study also found that when children attending spiritual education in Ethiopian Orthodox Church, some children come into street life due to insufficient basic needs such as clothes, and soaps. Consequently, this finding was inconsistence with former researchers.

Moreover, street children are terribly vulnerable to physical attack and grievance to exposed health problems. This study findings relating to health issues are working conditions, living conditions, eating systems, access to health services, and bureaucracy of assistance organization. Moreover, they are perpetually exposed to harsh weather conditions like intense sun, rain, and cold. Therefore, they are a vulnerable cluster of societies. This study claimed that most social problem that street children face is negligence like threats, insulting, strike, and stealing of personal properties by members of the general public right away.

\section{Conclusion}

This study has made an effort to investigate the circumstance, and problems of street children in Gondar city. This study attempted to answer the specific research tasks of studying children's experience using a qualitative research method. Thus, this study drawing conclusions on the circumstances, and problems, of street children in the study area, helped to street Children's narration about their forcing circumstances. From the finding of the study, the following conclusion is warranted. The street could be a supply of financial gain for children who live on the street. The street children are compelled by pull and push reasons. Consequently, this study shows that the prevalence of street children could be the result of the complicated interaction of divorce, parental detachment, and lack of families, poverty, cultural factors, peer pressure, geographical access, and improper-usage children by parents as reasons that force children living on streets. There are specific issues that were connected to children's experiences on the street. Thus, children living on the street faced abused and neglected, health issues, social exclusion, and violence by police and chase by militia patrol. Although some Street children might want to go back home due to the fear of parents, they remain on the street. Their narratives show that their feeling shame truly denies the return of children to families and therefore, the children become confused about wherever they belong.

\section{Recommendation}

Based on the findings obtained, in this study, the following foremost points are scholarly recommended. 
$>$ The government should fortify the families by using developing policies and strategies to enhance the mindset towards their child especially in rural families.

$>$ The government makes law and to ensures implementation of the legal guidelines concerning child rights and security and, educational systems.

$>$ Thus, every institution should consider street children to avoid children's vulnerability.

$>$ The government should be distribution equal education to all manifests within the communities concerning stigma and not get opportunities.

$>$ Both governmental and non-governmental organizations should be creating cognizance for society in the direction of young people on the street because society labelled them as theft criminal activities, burglary then they excluded via societies.

\section{References}

Astalin, P. K. (2013), Qualitative Research Designs : A Conceptual Framework, 2(1), 118-124.

Berg, B. L, (2001) Qualitative research methods for the social sciences, Allyn and Bacon, United States.

Bernard, H. R. (2002). Research methods in anthropology: Qualitative and quantitative approaches (3rd ed.) Walnut Creek, CA: Alta Mira Press

Birhanu, (2019) international journal of social work: Effects and Survival Strategies of street children, the Case of West Showa Zone in Ambo Town, Ethiopia.

Boafo, (2015), Livelihood Strategies of Street Children in Accra, PhD dissertation presented, at university of Ghana

Bondo, (2014), Being the Street: Causes, Survival Strategy and Societal Perception an Empirical Study of Street Children in Kathmandu MA thesis, at the University of NORDLAND.

Bryman, Alan (2008). Social research methods, New York: Oxford University Press Inc.

Creswell, J. W. (2009). Research Design: Qualitative, Approaches (4th ed.).

Densely, M. K and Joss, D. M. (2000), Street Children: Causes and Consequences, and Innovative Treatment Approaches, Work 15, pp. 217-225.

Denzin, N.K. \& Lincoln, Y.S. (2002) Handbook of qualitative research, 2nd ed, Sage Publications

Diriba.T, (2012), Contributing factors to Streetism and life Condition of street children: The Case of Nekemete Town MA thesis.

Erlbaum, L., Taylor, A., (2009,), Analyzing Qualitative Data, 39(3), 146-154.

FSCE (2003). "Sample Survey on: The Situation of Street Children in Eight Major Towns of Ethiopia". Forum on Street Children in Ethiopia, Addis Ababa, Ethiopa.

Girmachew,(2006), Livelihoods and survival strategies among migrant children in Addis Ababa Norwegian University of Science and Technology (NTNU) Faculty of Social Sciences and Technology Management, Trondheim Norway.

Grounded Theory: Practical Guide for Management, Business and Market Researches. Sage Publication Ltd.

Hecht, T, (2003), At Home in the Street: Street Children of Northeast Brazil. Cambridge University Press, Cambridge UK.

Kebede, S. K, (2015), the Situation of Street Children in Urban Centers of Ethiopia and the Role of NGO in Addressing their Socio-Economic Problems : The Case of Hawassa City,

Kibrom, B, (2008), Life in the streets of Adama: The situation of street children in a fast growing Ethiopian Town MA thesis at Addis Ababa University.

Lacey, A. (2007), Qualitative Data Analysis Authors.

Lalor, K. (1999). Street Children: A Comparative Perspective. Child Abuse and Neglect,

Lucchini, R. (1996), thestreet children and its image, Childhood, p 235-246.

Nieswiadomy, R. M. (1993), Foundations of nursing research. (2nd Edition .). Norwalk, CT: Appleton \& Lange.

Njeru, J. W (1989), Situation analysis for children in difficult circumstances. Congress proceedings report, Mombasa

Tatek, A, (2009,) Šik‘älla: the Survival Strategies of Ethiopian Child Beggars: Proceedings of the International Conference of Ethiopian Studies, ed. by SveinEge, Harald Aspen

Yogesph, (2006), Fundamental research methodology in social research method 